\title{
Fibrina Rica em Plaquetas (PRF) como auxiliar na Implantodontia Oral: relato de
}

\author{
caso \\ Platelet-Rich Fibrin (PRF) as an assistant in Oral Implantology: case report \\ Fibrina Rica en Plaquetas (PRF) como asistente en Implantología Oral: reporte de caso
}

Recebido: 18/11/2021 | Revisado: 24/11/2021 | Aceito: 26/11/2021 | Publicado: 09/12/2021

Lucas Borges Campos

ORCID: https://orcid.org/0000-0003-0044-0375

Faculdade Patos de Minas, Brasil

E-mail: lucasborgescampos100@gmail.com

Lia Dietrich

ORCID: https://orcid.org/0000-0001-7887-8591 Universidade Federal dos Vales do Jequitinhonha e Mucuri, Brasil E-mail: lia_dietrich@yahoo.com.br

Paulo César Segundo de Sousa

ORCID: https://orcid.org/0000-0003-0181-3890 Faculdade Patos de Minas, Brasil

E-mail: direcao.clinicas@faculdadepatosdeminas.edu.br

Cláudia Maria de Oliveira Andrade

ORCID: https://orcid.org/0000-0003-4529-8106 Faculdade Patos de Minas, Brasil

E-mail: Claudiamoacd@yahoo.com.br

Marcelo Dias Moreira de Assis Costa

ORCID: https://orcid.org/0000-0001-9148-3674

Universidade Federal de Uberlândia, Brasil

E-mail: gc.murilo.gc@gmail.com

Victor da Mota Martins

ORCID: https://orcid.org/0000-0001-6631-6161

Centro Universitário de Patos de Minas, Brasil E-mail: victortag@hotmail.com

\begin{abstract}
Resumo
O sangue é um elemento extremamente importante para o processo de cicatrização dos tecidos lesionados, tal fato é devido a presença de inúmeras células presentes neste as quais são essenciais para o desenvolvimento do processo fisiológico de cura. A PRF é um agregado plaquetário de segunda geração adquirido através da centrifugação de sangue autólogo, o que acaba diminuindo a aquisição de infecções transmissíveis de forma cruzada, fazendo com que este agregado seja extremamente seguro. O PRF vem sendo cada vez mais utilizado dentro da área cirúrgica odontológica principalmente nos procedimentos de exodontia de terceiro molar, instalação de implantes dentários, levantamento do seio maxilar, reparo de fenda alveolar, preservação do rebordo alveolar após exodontia, tratamento de comunicações buco-sinusais. Este trabalho objetiva relatar um caso clinico de instalação de implantes dentários ósseointegrados no qual foi empregado PRF para auxiliar no pós operatório do paciente. Foi realizado cirurgia em um paciente fumante, hipertenso, do sexo feminino de 58 anos de idade para instalação de dois implantes Cone Morse na região posterior inferior esquerda com posterior utilização de PRF para auxiliar no pós operatório. Após a realização do caso clinico relatado foi constatada a efetividade dos benefícios da PRF mencionados na literatura quando empregada nas cirurgias para instalação de implantes dentários.
\end{abstract}

Palavras-chave: Odontologia; Fibrina rica em plaquetas; Implantação dentária; Cirurgia bucal; Cicatrização.

\begin{abstract}
Blood is an extremely important element for the healing process of injured tissues, this fact is due to the presence of numerous cells present in it, which are essential for the development of the physiological healing process. PRF is a second-generation platelet aggregate acquired through autologous blood centrifugation, which ends up reducing the acquisition of cross-transmissible infections, making this aggregate extremely safe. The PRF has been increasingly used within the dental surgical area, especially in third molar extraction procedures, installation of dental implants, lifting the maxillary sinus, alveolar cleft repair, preservation of the alveolar ridge after extraction, treatment of oralsinusal communications. This paper aims to report a clinical case of installation of bone-integrated dental implants in which PRF was used to assist in the patient's postoperative period. A 58-year-old female smoker, hypertensive patient underwent surgery to install two Morse Cone implants in the lower left posterior region with subsequent use of PRF to
\end{abstract}


assist in the postoperative period. After performing the clinical case reported, the effectiveness of the benefits of PRF mentioned in the literature was verified when used in surgeries for installation of dental implants.

Keywords: Dentistry; Platelet-rich fibrin; Dental implantation; Oral surgery; Healing.

\section{Resumen}

La sangre es un elemento sumamente importante para el proceso de curación de los tejidos lesionados, este hecho se debe a la presencia de numerosas células presentes en ella, las cuales son fundamentales para el desarrollo del proceso fisiológico de curación. El PRF es un agregado plaquetario de segunda generación que se adquiere mediante centrifugación de sangre autóloga, que termina reduciendo la adquisición de infecciones de transmisión cruzada, lo que hace que este agregado sea extremadamente seguro. El PRF se ha utilizado cada vez más dentro del área quirúrgica dental, especialmente en procedimientos de extracción de terceros molares, instalación de implantes dentales, elevación del seno maxilar, reparación de hendiduras alveolares, preservación de la cresta alveolar después de la extracción, tratamiento de las comunicaciones orales-sinusales. Este artículo tiene como objetivo reportar un caso clínico de instalación de implantes dentales con integración ósea en el que se utilizó PRF para ayudar en el postoperatorio del paciente. Una paciente hipertensa, fumadora de 58 años, fue sometida a cirugía para instalar dos implantes de cono Morse en la región posterior inferior izquierda con el uso posterior de PRF para ayudar en el período postoperatorio. Luego de realizar el caso clínico reportado, se verificó la efectividad de los beneficios del PRF mencionado en la literatura cuando se utiliza en cirugías para instalación de implantes dentales.

Palabras clave: Odontología; Fibrina rica en plaquetas; Implantación dental; Cirugía oral; Curación.

\section{Introdução}

Durante o processo de cicatrização de lesões, o sangue possui um papel crucial para o aumento da taxa de regeneração dos tecidos danificados, uma vez que este é fonte de diversas células essenciais para a desenvolvimento do processo fisiológico de cura, chamadas de fatores de crescimento, coagulação e citocinas (Cunha, 2018).

As plaquetas são fragmentos citoplasmáticos anucleados, os quais possuem como célula medular progenitora o megacariócito (Ponte, 2020). As plaquetas, localizam-se em circulação durante um período aproximado de 7 a 10 dias, durante o qual exerce um papel fundamental no processo de hemóstase primaria, tais células exercem sua função através de adesão e agregação, criando uma região de pró-coagulação que gera o desenvolvimento de trombina e consequentemente, de fibrina (Dias, 2018; Ponte, 2020).

O potencial das plaquetas de realizar o aprimoramento da regeneração de tecidos duros e moles foi descoberto em 1974 (Mourão et al, 2015; Favero et al, 2017). Desde então vem sendo demonstrado através de investigações a capacidade das plaquetas uma vez isoladas do sangue periférico de aumentar a taxa de cicatrização, não apenas devido a coagulação promovida, mas também devido ao fato destas serem uma fonte autóloga de fatores de crescimento, possuidores de grânulos alfa, os quais possuem a capacidade de estimular a proliferação celular, remodelação da matriz e até angiogênese (Cunha, 2018; Mourão et al, 2015; Favero et al, 2017).

Desde o descobrimento das propriedades das plaquetas, diversos investigadores procuraram criar um sistema ideal, objetivando juntar os atributos vedantes da fibrina com os fatores de crescimento das plaquetas, para posteriormente realizar a sua deposição no local lesionado, viabilizando uma base natural para que se desenvolva a cicatrização e regeneração dos tecidos lesionados (Mallmann et al, 2013; Miron et al, 2011).

Após muitas pesquisas e inovações cientificas, passando pelos concentrados de plaquetários com adição de anticoagulante e pelas colas de fibrinas, em 2001 desenvolveu-se na França um novo grupo de concentrado plaquetário, este foi nomeado como Fibrina Rica em Plaquetas e se trata de uma matriz cicatricial totalmente autóloga, a qual é obtida por meio de uma centrifugação do sangue do paciente, não necessitando da adição de anticoagulantes (Peralvo et al, 2017).

O risco de se adquirir doenças transmissíveis, como hepatite e HIV é inexistente uma vez que a Fibrina Rica em Plaquetas é obtida utilizando exclusivamente sangue autólogo o que a torna extremamente segura (Agarwal et al, 2015; Choukroun et al, 2006).

Este concentrado plaquetário é utilizado em uma série de procedimentos cirúrgicos odontológicos, podendo citar 
como exemplo, sua utilização em procedimentos de exodontia de terceiro molar, instalação de implantes dentários, levantamento do seio maxilar, reparo de fenda alveolar, preservação do rebordo alveolar após exodontia, tratamento de comunicações buco-sinusais (Clark et al, 2006; Alves et al, 2020).

Após a colocação das Fibrinas Ricas em plaquetas, acontece liberação de fatores de crescimento, moléculas de adesão e citocinas pró e anti-inflamatórias por um período aproximado de 7 dias, auxiliando no processo de modulação da resposta inflamatória reparadora, ampliando tanto a neovascularização como a eficácia da regeneração tecidual da angiogênese, também ocorre a redução da dor pós-operatória e a diminuição do desenvolvimento de edema (Mourão et al, 2015; Peralvo et al, 2017; Favero et al, 2017). Estas propriedades possibilitaram o emprego deste biomaterial em numerosos procedimentos cirúrgicos odontológicos, como os já mencionados acima (Ponte, 2020; Mallmann et al, 2013).

Este trabalho objetiva relatar um caso clínico de instalação de implantes dentários osseointegrados no qual foi empregado PRF para auxiliar no pós operatório do paciente.

Foi realizado cirurgia em um paciente fumante, hipertenso, do sexo feminino de 58 anos de idade para instalação de dois implantes Cone Morse na região posterior inferior esquerda com posterior utilização de PRF para auxiliar no pós operatório.

\section{Metodologia}

Este estudo apresenta caráter qualitativo e descritivo e foi realizado por meio de um relato de um caso clínico de um paciente.

Para realização desse trabalho foi realizado uma pesquisa nas bases de dados on-line, localizados pelo mecanismo de busca do SciELO, PubMed e LILACS usando como palavras-chave "Fibrina rica em plaquetas", "Implantodontia", "Biomaterial", e como descritores "Surgery, Oral", "Wound Healing”, "Platelet-rich fibrin".

$\mathrm{O}$ paciente do presente artigo concordou em participar deste trabalho e assinou o Termo de Consentimento Livre e Esclarecido (TCLE), sendo o projeto tramitado pelo Comitê de Ética e Pesquisa com Seres Humanos da Faculdade Patos de Minas, autorizado pelo número de parecer: 4.683.415.

\section{Relato de Caso}

Paciente fumante, hipertensa, sexo feminino, 58 anos de idade, procurou o consultório odontológico queixando-se da ausência de alguns dentes, problema com a mastigação e baixa autoestima.

$\mathrm{Na}$ anamnese a paciente relatava a extração dos dentes de forma precoce, sendo que o principal motivo seria a forma de tratamento na época (sic). No exame intraoral, apresentava ausência do segundo molar inferior esquerdo (37). (Figura 1). 
Figura 1. Visão intraoral da ausência do segundo moral inferior esquerdo.

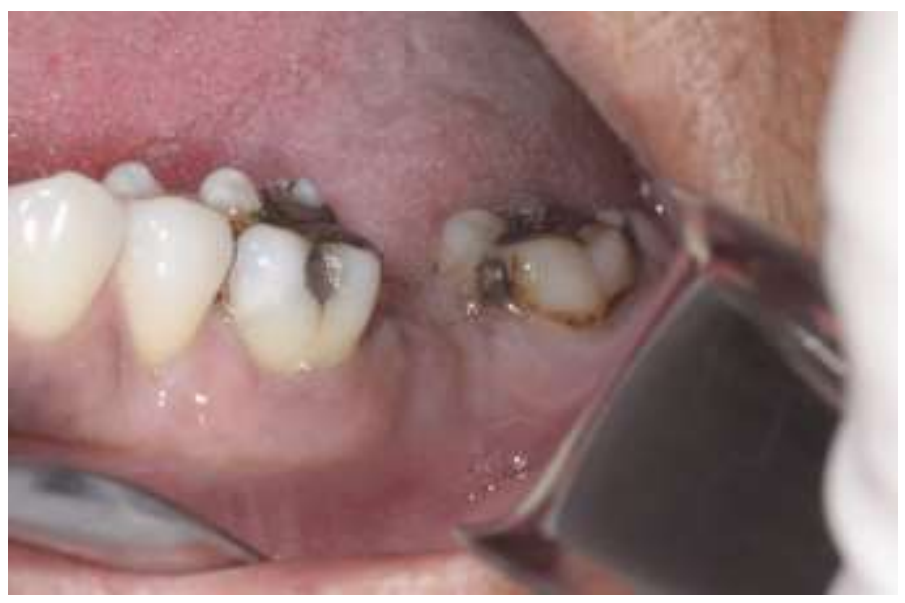

Fonte: Autores.

Durante a consulta inicial, foi sugerido a reabilitação com prótese parcial removível (PPR), prótese parcial fixa ou implantes osseointegrados, onde a paciente relatou o desejo da reabilitação com implantes dentários, e foi proposto um planejamento abrangendo a instalação de implantes osseointegráveis nas regiões com falhas dentarias.

Com a finalidade de planejar a reabilitação, foi solicitado exames por imagem (radiográfico) (Figura 2). Ao analisar o exame radiográfico observou-se lesão periapical nas duas raízes do dente 36 , onde seria indicado o tratamento endodôntico previamente à instalação do implante no 37. Entretanto ao analisar as imagens da tomografia computadorizada, percebeu falta de suporte ósseo no dente 36, principalmente na face vestibular, levando a um prognóstico duvidoso.

Figura 2. Radiografias periapicais prévias.

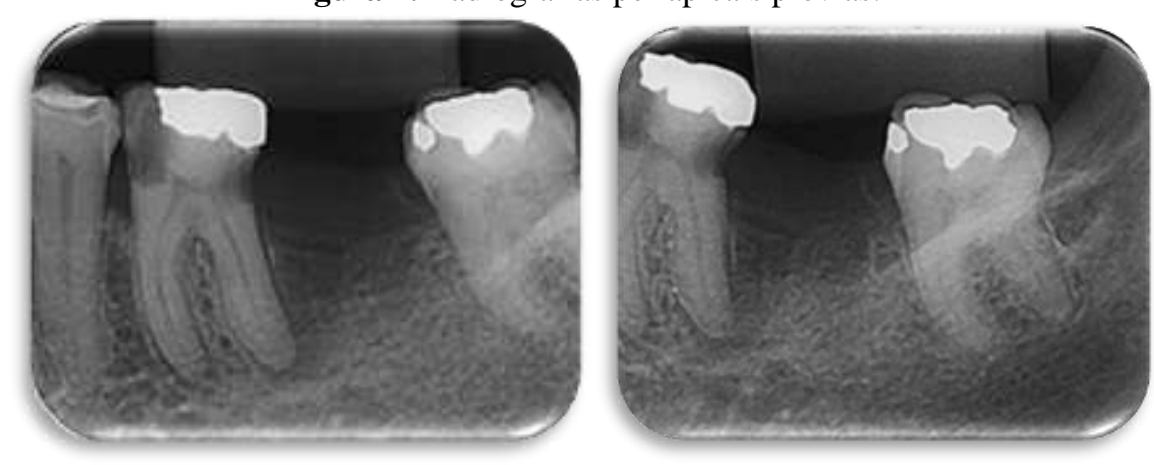

Fonte: Autores.

A paciente optou por fazer o tratamento reabilitador dos dentes 36 e 37 inicialmente, deixando o tratamento das demais áreas para outro momento futuro. Delineado o plano de tratamento reabilitador, foi recomendado ao paciente, a extração do dente 36 e instalação de dois implantes na região posterior inferior esquerdo, tendo total aprovação da paciente.

Como terapêutica pré-operatória foi administrado 1 hora antes Amoxicilina $1 \mathrm{~g}$ e Dexametasona 4g. Inicialmente, foi realizado a coleta de sangue da paciente, cerca de 70mL, com o uso do sistema fechado à vácuo de coleta e tubos de vidro sem aditivos (Figura 3A). Esse material foi colocado em uma centrifuga, e então centrifugado para obtenção das membranas de PRF (Figura 3B). 
Figura 3. A) Coleta de sangue em sistema à vácuo. B) Centrifugação do sangue coletado.
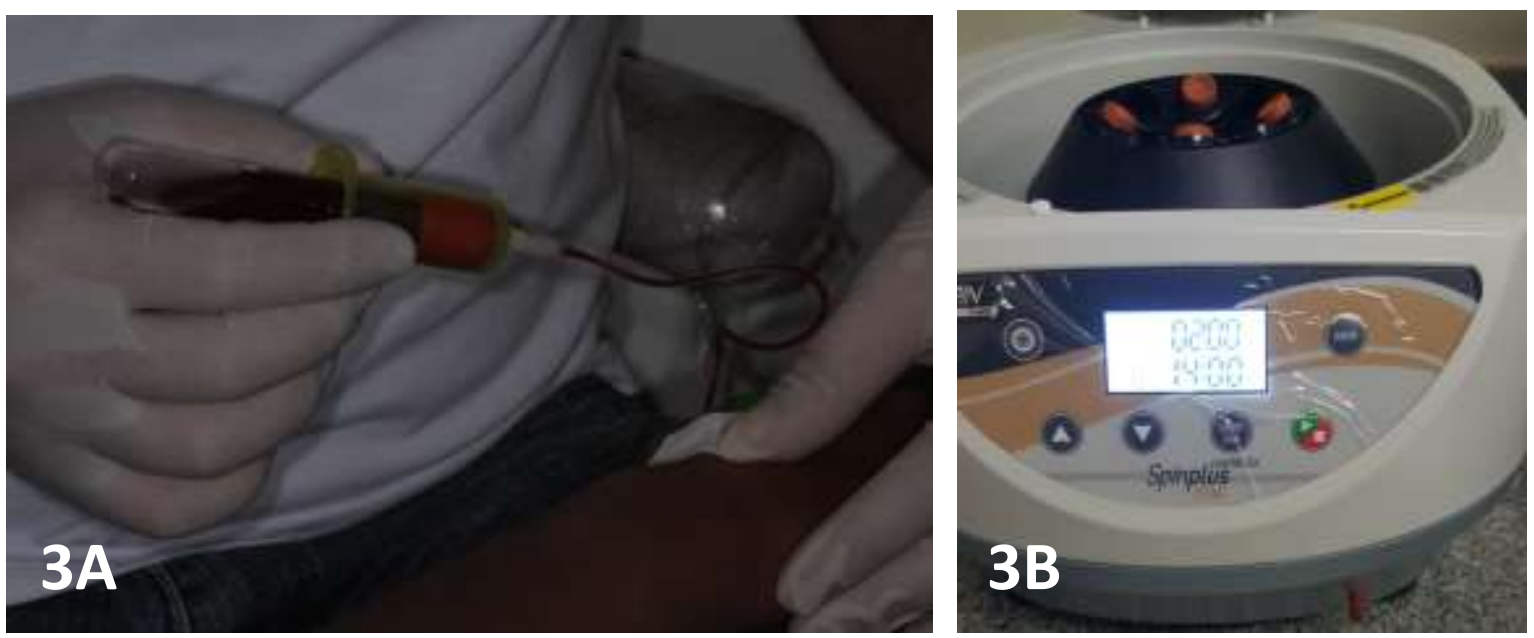

Fonte: Autores.

Logo após, o procedimento cirúrgico foi executado em ambiente odontológico higienizado. Dando início com a assepsia intraoral com Clorexidina $0,12 \%$ e extraoral com $2 \%$ sob aplicação da anestesia local com Lidocaína na concentração $2 \%$ com vasoconstritor epinefrina 1:100.000, utilizando as técnicas de bloqueio regional do nervo alveolar inferior, bucal e lingual, pois seria realizado a exodontia do dente 36. A sindesmotomia no dente 36 foi feita com bisturi lâmina 15, deslocadores de Molt 2/4 e 9, separando o tecido gengival.

Efetuado a sindesmotomia, foi feito a luxação com alavanca apical reta, com a técnica de movimentos de cunha e de alavanca. Após mobilidade foi feito o uso do fórceps 17, movimento de lateralidade ocorrendo sua respectiva remoção. Posteriormente foi feita curetagem dos tecidos com a Cureta de Lucas, e irrigação com Soro Fisiológico 0,9\% do alvéolo.

Concretizado a extração do dente 36 (Figura 4A), foi realizado uma incisão do tipo Avelanal, e descolamento muco periosteal do tecido gengival na região onde edêntula distal ao 36 (Figura 4B).

Figura 4. A) Exodontia realizada do elemento dentário 36. B) Descolamento muco periosteal na região onde seria o elemento dentário 37 .
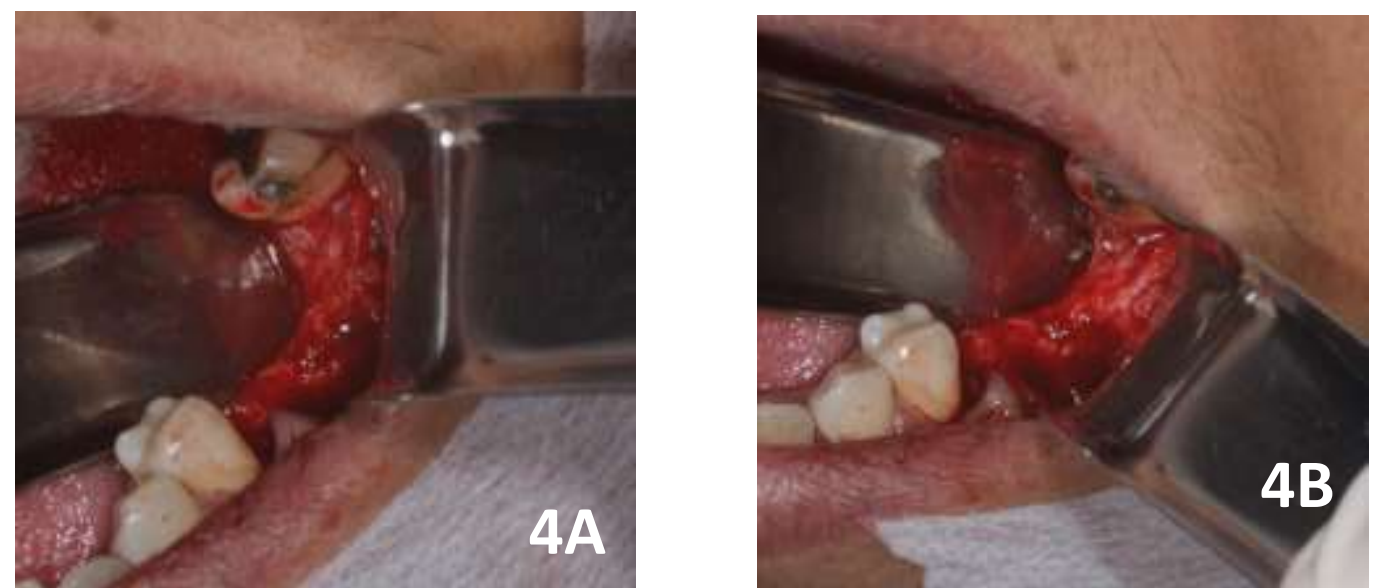

Fonte: Autores.

O tipo de concentrado sanguíneo obtido foi em forma de membrana, onde a mesma foi produzida através da obtenção do L-PRF (Figura 5A). Levadas a mesa cirúrgica, onde foram preparados para serem utilizadas no procedimento (Figura 5B). 
Figura 5. A) Membrana de L-PRF após a separação do coágulo. B) Membranas de L-PRF preparadas para serem inseridas no sitio cirúrgico.

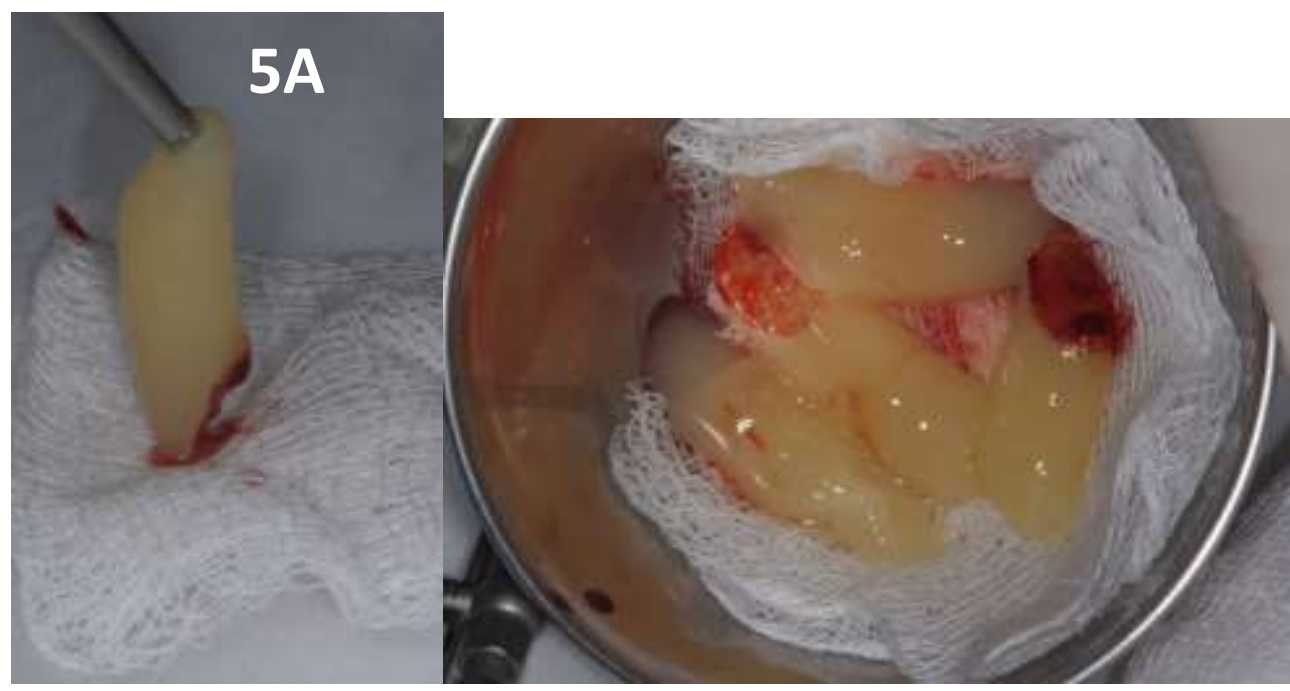

Fonte: Autores.

Previamente à colocação do L-PRF foi realiza a instalação dos implantes de cone morse na região dos dentes 36 e 37 (Figura 6A).

Figura 6. Implantes instalados na região dos elementos dentários 36 e 37.

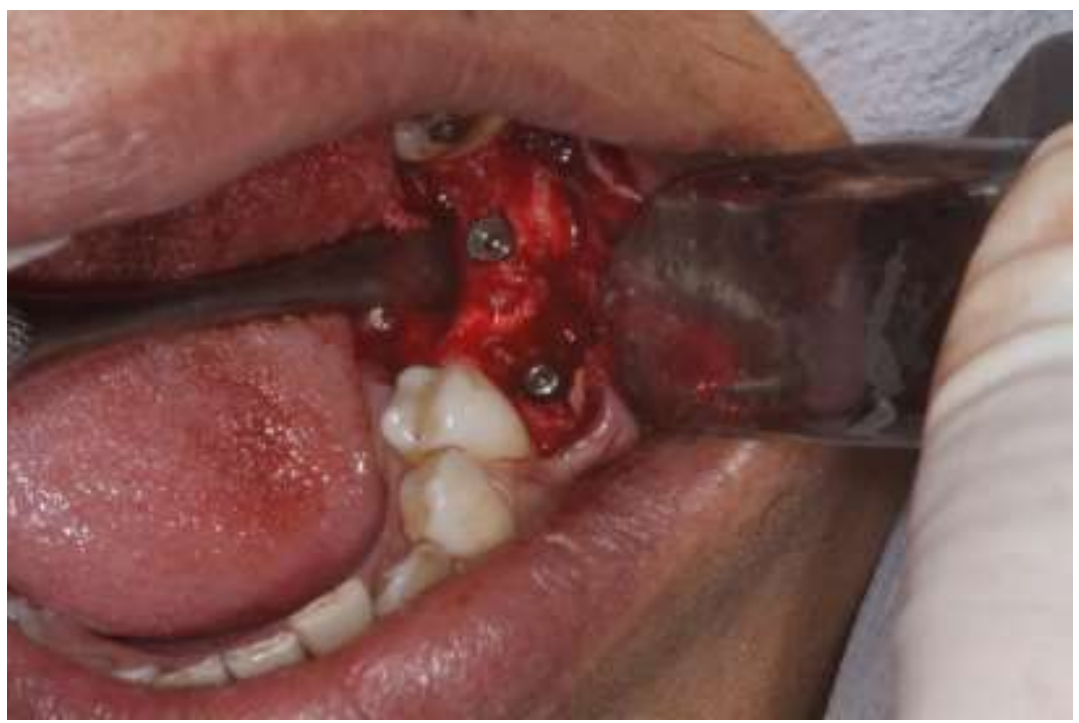

Fonte: Autores.

$\mathrm{Na}$ sequência as membras de L-PRF foram colocadas preenchendo o alvéolo do dente 36 e o recobrimento dos implantes (Figura 7A e 7B), reposição passiva dos tecidos e sutura de ponto simples com fio de Nylon 5-0 (Figura 7C). Foram realizadas as devidas recomendações pós operatórias, incluindo uso de medicamentos: Dipirona sódica 500mg de 6/6 horas por 2 dias, Ibuprofeno 600mg de 6/6 horas por 3 dias e Amoxicilina 500mg de 8/8 horas por 7 dias. Uma semana após a cirurgia foi feita remoção de pontos, não havendo nenhuma complicação pós-operatória e foi aguardado o período de osseointegração, estimando o decorrer de 4 a 6 meses para futura instalação das próteses. Foi realizado radiografia pós instalação dos implantes, para controle (Figura 8). 
Figura 7. A) Membranas colocadas no alvéolo na região do elemento 36. B) Recobrimento dos implantes com a membranas. C) Suturas feita com fio de Nylon 5-0.

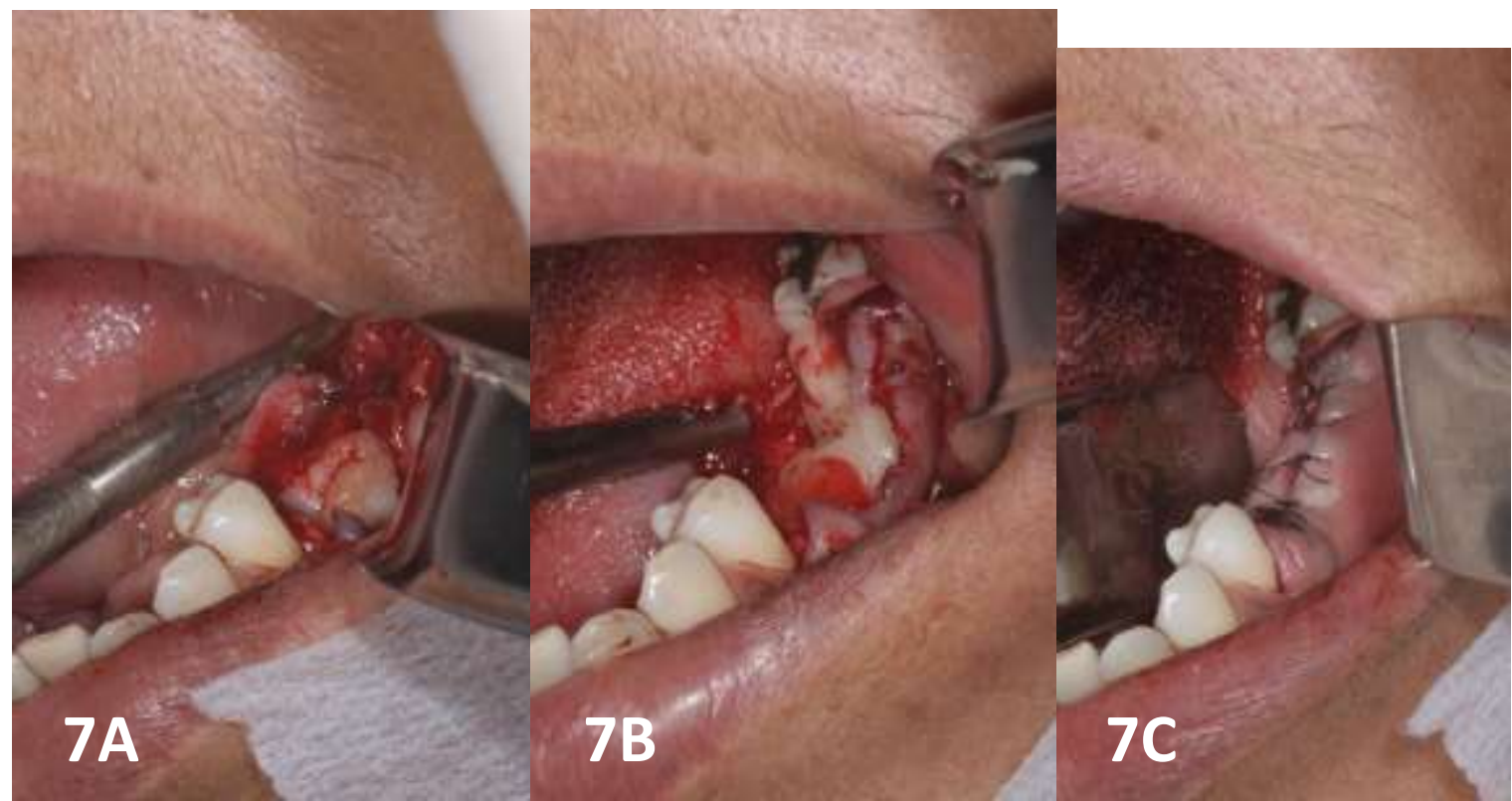

Fonte: Autores.

Figura 8. Radiografia periapical pós instalação implantes.
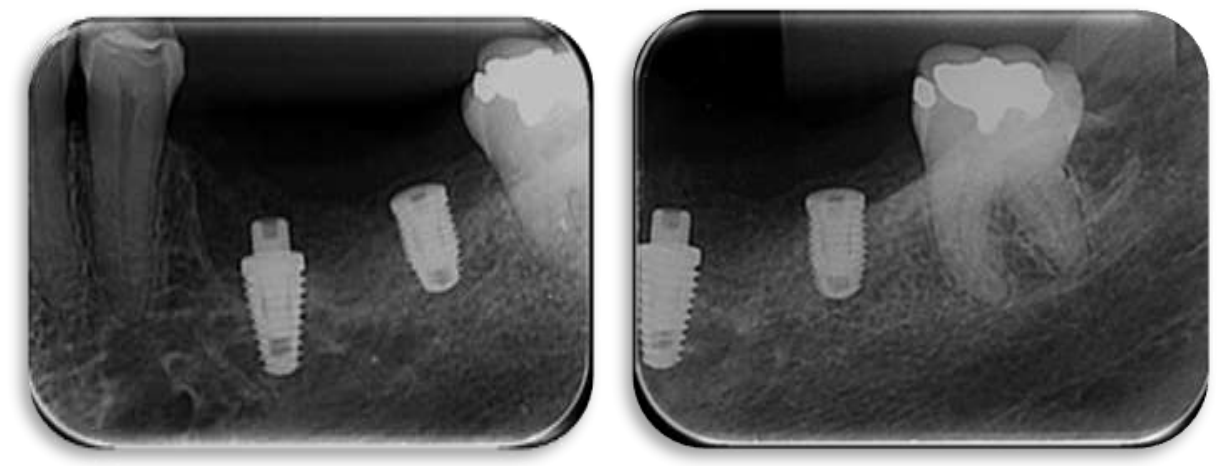

Fonte: Autores.

Após o período de osseointegração (Figura 9A), foi realizado a reabertura e instalação dos pilares protéticos (munhão universal) e confecção das coroas provisórias (Figura 9B). 
Figura 9. A) Área cirúrgica cicatrizada. B) Instalados os pilares protéticos e as coroas provisórias.
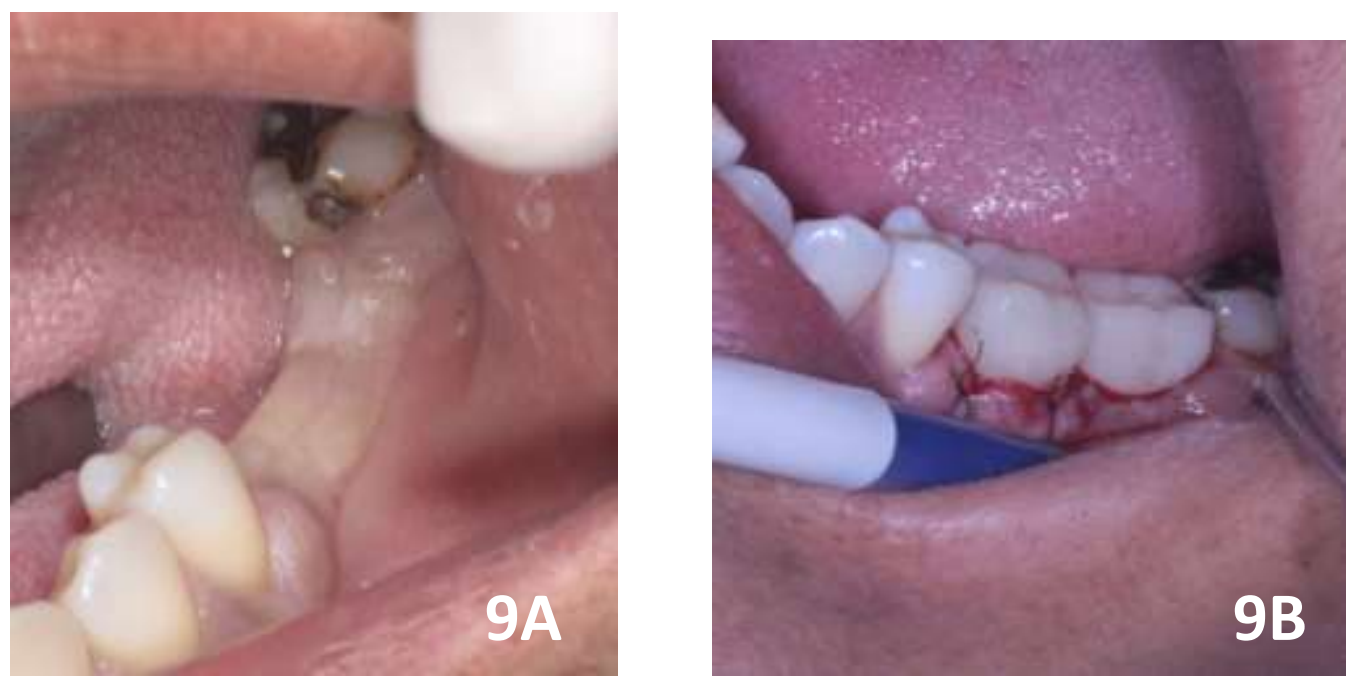

Fonte: Autores.

\section{Discussão}

Para a realização deste caso foi utilizado a Fibrina Rica em Plaqueta e Leucócitos Avançada (L-PRF), seguindo o protocolo de centrifugação de 1300 RPM, com 208g de força centrifuga, por 8 minutos o qual é explicado no estudo de Cunha (Cunha, 2018).

Optou-se por empregar a instalação imediata dos implantes juntamente com a L-PRF, uma vez que, a instalação destes juntamente com a L-PRF amplia a área de contato osso-implante, fato este que favorece o processo de osseointegração e torna o pós operatório mais seguro e confortável, tais fatos também são constatados em estudos como o de Cunha (Cunha, 2018).

O uso da PRF dentro da área odontológica vem aumento a cada dia, tal fato é considerado uma boa notícia tanto para os implantodontistas que terão uma maior segurança quanto cicatrização pós cirúrgica quanto para os pacientes que além da melhor cicatrização terão um pós operatório mais confortável, uma vez que, tanto a sintomatologia dolorosa quanto a formação de edema são reduzidas quando se faz uso da PRF, tal fato pode ser observado em diversos estudos como o de Aires et al (Aires et al., 2020).

Além de auxiliar na cicatrização das feridas pós cirúrgicas o emprego de PRF na implantodontia também auxilia quando se é necessário a inserção de enxerto ósseo, uma vez que, a PRF também funciona como um aglutinador de enxertos, tal fato pode ser constatado no trabalho de Resende et al (Resende et al., 2020).

Clark ressalta em seu trabalho o fato de que apesar do uso da PRF dentro da área cirúrgica odontológica ser extremamente elogiada na literatura, é extremamente importante ser cauteloso diante das diversas divergências a respeito de suas indicações e vantagens presentes na literatura existentes (Clark, 2006).

Apesar de diversos autores exporem resultados positivos acerca da melhora na cicatrização uma vez utilizado PRF, outros ainda requerem a realização de mais estudos a respeito da cicatrização de tecidos duros como é o caso de Hak (Hak, 2020).

No presente estudo, alguns trabalhos apontam as limitações do uso do PRF em cirurgias gerais, o profissional deve estar apto para saber realizar a manipulação do PRF e as suas combinações clínicas e suas tecnologias, além disso, o profissional precisa- se de agilidade durante a coleta do sangue do paciente e logo após ser levado para centrifuga. Por essa razão se ocorre atraso durante essas etapas, o sangue começa seu processo de coagulação, gerando uma irregularidade durante o processo de polimerização como apontado nos estudos de Hak (Hak, 2020).

Um dos grandes diferenciais do emprego da PRF, além da melhora do processo de cicatrização, é a sua capacidade de 
reduzir o nível de agressão das cirurgias para instalação de implantes dentários, o que acaba auxiliando para que ocorram tratamentos menos traumáticos e mais rápidos, tal fato pode ser observado no estudo de Mendonça (Mendonça, 2018).

É possível encontrar na literatura estudos que afirmam que devido ao emprego da PRF, é possível realizar protocolos de carga precoce em um número considerável de paciente, tal fato pode ser observado no trabalho de Aires et al (Aires et al., 2020).

\section{Conclusão}

Após realizar uma análise criteriosa da literatura disponível acerca dos concentrados sanguíneos, bem como seu emprego na implantodontia e a realização do caso clínico relatado neste trabalho, conclui-se que o emprego do L-PRF na implantodontia traz benefícios reais para o paciente relacionados principalmente a uma melhoria da qualidade dos tecidos periodontais na região, principalmente nas áreas de implante imediato, contribuindo para a cicatrização em primeira intenção, favorecendo a cicatrização.

\section{Referências}

Agarwal, A., Cupta, N. D. (2016) Platelet rich fibrin combined with decalcified freeze-dried bone allograft for the treatment of human intrabony periodontal defects: a randomized split mouth clinical trail. Acta Odontologica Scandinavica, 36 , https://www.tandfonline.com/doi/abs/10.3109/00016357.2015.1035672

Aires, C. C. G., Figueiredo, E. L., Pereira, V. B. S., Vasconcellos, R. J. H., Sabino, M. E. B., \& Medeiros, M. F. (2020). Terapias regenerativas em implantodontia: avanços no uso da Fibrina rica em plaquetas (PRF). Revista Eletrônica Acervo Saúde, (39), e2393. https://acervomais.com.br/index.php/saude/article/view/2393

Alves, F. O., Camargo, F. F., Duré, C. L., Naujorks, C. C., Wagner, M., Silva, V. D. et al. (2011). Efeito do Plasma Rico em Plaquetas e da Fibrina Rica em Plaquetas na cicatrização de feridas cutâneas em ratos. Anais do XII Salão de Iniciação Cientifica, Rio Grande do Sul, PUCRS. https://editora.pucrs.br/anais/seminarioic/20112/4/6/2/3/2.pdf

Alves, L. A. L. S., Silva, F. B. M., Lacerda, C. B. V., Louro, R. S., \& Resende, R. F. B. (2020). Fibrina rica em plaquetas (PRF) como tratamento de comunicação buco-sinusal: relato de caso. Revista Fluminense de Odontologia, 53, 84-95. https://periodicos.uff.br/ijosd/article/view/39870

Choukroun, J., Diss, A., Simonpieri, A., Girard, M. O., Schoeffler, C., Dohan, S. L. et al. (2006). Platelet-rich fibrin (PRF): a second-generation platelet concentrate. Part IV: clinical effects on tissue healing. Oral surgery, oral medicine, oral pathology, oral radiology, and endodontics, 101(3), e56-e60. https://pubmed.ncbi.nlm.nih.gov/16504852/

Clark, R. A. F. (2006). Fibrin and Wound Healing. Annals of the New York Academy of Sciences, 355-367. https://nyaspubs.onlinelibrary.wiley.com/doi/10.1111/j.1749-6632.2001.tb03522.x

Cunha, V. P. M. (2018). L-PRF: uma nova tendência de regeneração tecidular. Tese de Mestrado em Ciências da Saúde, Instituto Universitário de Ciência da Saúde, Gandra. https://repositorio.cespu.pt/handle/20.500.11816/3157

Dias, A. M. V. (2018). PRF-indicações e aplicações clínicas em medicina dentária. Tese de Mestrado em Ciências da Saúde, Instituto Universitário de Ciência da Saúde, Gandra. https://repositorio.cespu.pt/bitstream/handle/20.500.11816/2990/MIMD_RE_21664_anadias.pdf?sequence=1\&isAllowed=y

Favero, H. R. Z. (2017). Revisão comparativa entre agregados plaquetários e sangue total relacionados com osseointegração e titânio. Trabalho de Conclusão de Curso, Universidade Federal de Santa Catarina, SC. https://repositorio.ufsc.br/handle/123456789/181325

Hak, S. (2020). L-prf: aplicação clínica em implantodontia. Trabalho de Conclusão de curso, Centro Universitário UNIFACVEST, Lages, SC. https://www.unifacvest.edu.br/assets/uploads/files/arquivos/6dd19-hak,-s.-1-prf---aplicacao-clinica-em-implantodontia.-odontologia.-lages_-unifacvest,-202001_.pd

Karimi, K., \& Rockwell, H. (2019). The Benefits of Platelet-Rich Fibrin. Facial plastic surgery clinics of North America, 27(3), 331-340. https://pubmed.ncbi.nlm.nih.gov/31280847/

Mallmann, F., Lago, P. E. W., \& Bora A. D. (2013). Uso de fibrina rica em plaquetas (PRF) no tratamento de perfurações da membrana sinusal. Full Dent. Sci, 5(17), 59-66. https://pesquisa.bvsalud.org/portal/resource/pt/lil-706297

Medonça, R. E. (2018). Fibrina Rica em Plaquetas e Leucocitos (L-PRF) e sua Importância na Implantodontia. Trabalho de Conclusão de Curso, Faculdade Sete Lagoas, MG. https://faculdadefacsete.edu.br/monografia/files/original/b9c4a4a4baa0dfc985c138f885eb24f2.pdf

Miron, R. J., Fujioka-Kobayashi, M., Hernandez, M., Kandalam, U., Zhang, Y., Ghanaati, S., \& Choukroun, J. (2017). Injectable platelet rich fibrin (i-PRF): opportunities in regenerative dentistry?. Clinical oral investigations, 21(8), 2619-2627. https://pubmed.ncbi.nlm.nih.gov/28154995/

Miron, R. J., Zucchelli, G., Pikos, M. A., Salama, M., Lee, S., Guillemette, V., Fujioka-Kobayashi, M., Bishara, M., Zhang, Y., Wang, H. L., Chandad, F., Nacopoulos, C., Simonpieri, A., Aalam, A. A., Felice, P., Sammartino, G., Ghanaati, S., Hernandez, M. A., \& Choukroun, J. (2017). Use of platelet-rich fibrin in regenerative dentistry: a systematic review. Clinical oral investigations, 21(6), 1913-1927. https://pubmed.ncbi.nlm.nih.gov/28551729/ 
Research, Society and Development, v. 10, n. 16, e132101623503, 2021

(CC BY 4.0) | ISSN 2525-3409 | DOI: http://dx.doi.org/10.33448/rsd-v10i16.23503

Mourão, C. F. A. B., Valiense, H., Melo, E. R., Mourão, N. B, M, F, \& Maia, M. D. C. (2015). Obtenção da fibrina rica em plaquetas injetável (i-PRF) e sua polimerização com enxerto ósseo: nota técnica. Rev. Col. Bras. Cir. 42(6), 421-423. https://www.scielo.br/scielo.php?pid=S010069912015000700421\&script=sci_arttext\&tlng=pt

Ogundipe O. K., Ugboko V. I., \& Owotade F. J. (2011). Can Autologous Platelet-Rich Plasma Gel Enhance Healing After Surgical Extraction of Mandibular Third Molars? Journal of Oral and Maxillofacial Surgery, 69(9), 2305-2310. https://europepmc.org/article/med/21550158

Peralvo, A. O. S., García A. S., \& Fluente L. A. (2017). Nuevas tendencias en regeneración tisular: fibrina rica en plaquetas y leucocitos. Revista Española de Cirugía Oral y Maxilofacial, 39(2), 91-98. http://scielo.isciii.es/scielo.php?script=sci_abstract\&pid=S1130-05582017000200091

Ponte, J. S. (2020). Avaliação histomorfométrica de alvéolos dentários humanos pós-extração tratados com fibrina autóloga, fosfato de cálcio bifásico ou sua associação. Tese de Mestrado em Biotecnologia, Universidade Federal do Ceará, Sobral, CE. http://www.repositorio.ufc.br/handle/riufc/53198

Resende, R. F. B., Pereira, I. V., Cardoso, A., Machado, A. N., \& Pinheiro, A.R. (2020). Quando indicar o uso da fibrina rica em plaquetas (prf) na implantodontia oral? Revisão de literatura. Revista Fluminense de Odontologia. 54, 68-80. https://periodicos.uff.br/ijosd/article/view/41000

Rodrigues, E. D. R. (2020). Avaliação da reparação óssea após exodontias de terceiros molares inclusos com a utilização da fibrina rica em plaquetas e leucócitos (L-PRF). Dissertação de Mestrado em Odontologia, Universidade de Pernambuco, Camaragibe, PE. http://w2.files.scire.net.br/atrio/upeodontologia_upl/THESIS/161/dissertao_werton_daniel_rocha_rodrigues_20200312114846578.pdf

Rodrigues, G., Fabris, V., Mallmann, F., Rech, C., Carvalho, R., \& Ruschel, G. (2016). Fibrinas ricas em plaquetas, uma alternativa para regeneração tecidual: revisão de literatura. Journal of Oral Investigations, 4(2), 57-62. https://seer.imed.edu.br/index.php/JOI/article/view/1526

Seidler, D. K. (2019). Avaliação da fibrina rica em plaquetas na regeneração de tecidos orais: uma revisão de literatura. Trabalho de Conclusão de Curso, Universidade Federal de Santa Catarina, SC. https://repositorio.ufsc.br/handle/123456789/201601

Yelamali, T., \& Saikrishna, D. (2015). Role of platelet rich fibrin and platelet rich plasma in wound healing of extracted third molar sockets: a comparative study. Journal of maxillofacial and oral surgery, 14(2), 410-416. https://www.ncbi.nlm.nih.gov/pmc/articles/PMC4444657/ 